\title{
Selective Migration of Subpopulations of Bone Marrow Cells along an SDF-1 $\alpha$ and ATP Gradient
}

\author{
Michael Laupheimer, ${ }^{1}$ Anna Skorska, ${ }^{1}$ Jana Große, ${ }^{1}$ Gudrun Tiedemann, ${ }^{1}$ \\ Gustav Steinhoff, ${ }^{1}$ Robert David, ${ }^{1}$ and Cornelia A. Lux ${ }^{1,2}$ \\ ${ }^{1}$ Reference and Translation Center for Cardiac Stem Cell Therapy, University of Rostock, 18057 Rostock, Germany \\ ${ }^{2}$ RTC, BMFZ, Schillingallee 68, 18057 Rostock, Germany \\ Correspondence should be addressed to Cornelia A. Lux; cornelia.lux@med.uni-rostock.de
}

Received 17 September 2014; Revised 3 December 2014; Accepted 5 December 2014; Published 31 December 2014

Academic Editor: Paolo De Fabritiis

Copyright (C) 2014 Michael Laupheimer et al. This is an open access article distributed under the Creative Commons Attribution License, which permits unrestricted use, distribution, and reproduction in any medium, provided the original work is properly cited.

Both stem cell chemokine stromal cell-derived factor- $1 \alpha$ (SDF-1 $\alpha)$ and extracellular nucleotides such as adenosine triphosphate (ATP) are increased in ischemic myocardium. Since ATP has been reported to influence cell migration, we analysed the migratory response of bone marrow cells towards a combination of SDF-1 and ATP. Total nucleated cells (BM-TNCs) were isolated from bone marrow of cardiac surgery patients. Migration assays were performed in vitro. Subsequently, migrated cells were subjected to multicolor flow cytometric analysis of CD133, CD34, CD117, CD184, CD309, and CD14 expression. BM-TNCs migrated significantly towards a combination of SDF-1 and ATP. The proportions of CD34+ cells as well as subpopulations coexpressing multiple stem cell markers were selectively enhanced after migration towards SDF-1 or SDF-1 + ATP. After spontaneous migration, significantly fewer stem cells and CD184+ cells were detected. Direct incubation with SDF-1 led to a reduction of CD184+ but not stem cell marker-positive cells, while incubation with ATP significantly increased CD14+ percentage. In summary, we found that while a combination of SDF-1 and ATP elicited strong migration of BM-TNCs in vitro, only SDF-1 was responsible for selective attraction of hematopoietic stem cells. Meanwhile, spontaneous migration of stem cells was lower compared to BM-TNCs or monocytes.

\section{Introduction}

The contribution of bone marrow cells to cardiac regeneration has been shown by Asahara et al. [1], and, to enhance the efficacy of this physiological mechanism, transplantation of bone marrow cells has since been performed in multiple experimental and clinical studies [2-7]. As the retention of transplanted cells in the myocardium is limited [8] and targeting is crucial for therapeutical effect, approaches to understand and manipulate homing of cells towards sites of injury are of high importance. Among the known factors recruiting bone marrow cells to the heart, SDF-1, a chemokine ligand of the G protein coupled receptor CD184 (CXCR-4), is the most prominent. SDF-1 guides the homing of circulating hematopoietic stem cells towards their bone marrow niches [9]. As SDF-1 is regulated by hypoxia inducible factor- $1 \alpha$ and thus depends on oxygen tension, it is overexpressed in hypoxic tissues $[10,11]$. SDF-1 was demonstrated to be upregulated in rat hearts as early as one hour after induction of ischemia by LAD ligation [12]. After a myocardial infarction, the level of SDF-1 is increased sevenfold [13]. Abbott et al. demonstrated that SDF-1 upregulation after myocardial infarction is necessary for cardiac recruitment of bone marrow cells in a mouse model [14].

However, additional factors with a putative influence on cellular migration are present in injured myocardium. Besides growth factors such as vascular endothelial growth factor (VEGF), interleukin- (IL-) 1 and IL-6, tumor necrosis factor- $\alpha$ (TNF- $\alpha$ ), and complement factors, which are present in infarcted tissue $[15,16]$, extracellular nucleotides are increased under hypoxic conditions. Adenosine triphosphate (ATP) has been shown to be released in isolated human hearts [17] as well as in cardiomyocytes [18] in response to ischemia. Similarly, in a rat model of cardiac ischemia, a release of uridine triphosphate (UTP) into the circulation was observed [19]. 
Nucleotides have been implied to play a crucial role in spontaneous migration, if not chemotaxis, of multiple cell types [20]. Neutrophil spontaneous migration is enhanced by ATP, which serves as an autocrine amplifier of chemotactic signals for the cells [21]. Human umbilical cord endothelial cells migrate towards ATP as well as UTP in vitro [22]. Rossi et al. demonstrated that nucleotides induce migration of isolated hematopoietic stem cells [23]. In light of these findings, induction or amplification of bone marrow cell motility by nucleotides seems likely.

Many progenitor cell populations as well as differentiated cells have been invoked as regenerative cell populations in bone marrow. To date, a major proportion of clinical trials have been conducted with nucleated bone marrow cells (BMTNCs) [24]. Which of the multiple cell populations contained in BM-TNCs migrate towards the infarcted myocardium in humans remains to be clarified. In the present study, we performed in vitro migration analyses of a BM-TNC product destined for clinical therapy, with a focus on the contained hematopoietic stem cell populations. SDF-1, ATP, and a combination thereof were employed as migratory stimuli.

\section{Materials and Methods}

Bone marrow aspirates were collected from informed donors who gave written consent to the use of their aspirates for research according to the Declaration of Helsinki. The study was approved by University of Rostock Ethical Committee (registered as number A 2010 23) as of April 29, 2010. Bone marrow was aspirated from the sternum immediately before median sternotomy and heparinized (250 i.E./mL).

2.1. BM-TNC Isolation. BM-TNCs were processed using the Res-Q 60 BMC System (Thermo Genesis Corp.) according to the manufacturer's instructions. In brief, bone marrow was filtered $(200 \mu \mathrm{m})$ and transferred to a tube containing a floating chamber. The tube was centrifuged, resulting in density-specific cell selection in the chamber, from where cells were gathered via sterile tubing in a syringe.

2.2. Characterization of Freshly Prepared BM-TNC. Cellular composition of starting material BM and cellular product BM-TNCs were analyzed by hemogram (measurement performed by the Institute of Clinical Chemistry and Laboratory Medicine (ILAB), University of Rostock, on a Sysmex XE 5000 machine, Sysmex GmbH, Germany).

\subsection{In Vitro Migration Assay (Modified Boyden Chamber).} Stock solutions of reagents were prepared as follows: adenosine triphosphate disodium salt (ATP, Sigma-Aldrich) was dissolved at a concentration of $4.5 \mathrm{mg} / \mathrm{mL}$ in phosphate buffer (DPBS w/o calcium and magnesium, PAN-Biotech $\mathrm{GmbH}$, Germany), sterile-filtered, and stored at $-80^{\circ} \mathrm{C}$. Recombinant human stromal cell-derived factor-1 (SDF-1, PAN-Biotech) was dissolved in PBS containing $0.1 \%$ bovine serum albumin (BSA, Sigma-Aldrich Co., USA) at a concentration of $100 \mu \mathrm{g} / \mathrm{mL}$ under sterile conditions and kept at $-20^{\circ} \mathrm{C}$. Furthermore, $24 \mathrm{~mm}$ transwell inserts $(3 \mu \mathrm{m}$ pore size, Corning Inc., USA) were coated with $10 \mathrm{ng} / \mathrm{mL}$ fibronectin (Human
TABLE 1: Antibody cocktail for multicolor staining (flow cytometry).

\begin{tabular}{lcc}
\hline Antibody & Fluorochrome & Manufacturer \\
\hline CD34 & FITC & Miltenyi Biotec \\
CD133 & PE & Miltenyi Biotec \\
CD184 & PE-Cy5 & $\begin{array}{c}\text { Becton Dickinson } \\
\text { (BD), USA }\end{array}$ \\
CD117 & PE-Cy7 & BD \\
CD309 & APC & Miltenyi Biotec \\
CD14 & V450 (Pacific Blue) & BD \\
CD45 & V500 (AmCyan) & BD \\
Live dead stain & $\begin{array}{c}\text { Near IR (detection } \\
\text { channel: APC-Cy7) }\end{array}$ & Life Technologies \\
\end{tabular}

Plasma Fibronectin, Merck Millipore, USA) in PBS for 1 hour at room temperature (RT). After washing the inserts three times with PBS, $1 \times 10^{6}$ BM-TNCs per well were seeded into them in $1.5 \mathrm{~mL}$ RPMI (PAN-Biotech) containing $1 \%$ BSA. Bottom chambers were filled with $2.6 \mathrm{~mL}$ of RPMI $1 \%$ BSA for evaluation of spontaneous migration or with corresponding amounts of medium containing $100 \mathrm{ng} / \mathrm{mL}$ SDF-1, $100 \mu \mathrm{M}$ ATP, or both. Cells were cultivated in the migration chambers or in 6-well culture plates (incubation control, incubation with SDF-1/SDF-1 + ATP) for $24 \mathrm{~h}$ at $37^{\circ} \mathrm{C} 5 \% \mathrm{CO}_{2}$. To collect migrated cells, inserts were taken out of the migration chambers and cells in the bottom wells were resuspended, transferred to tubes, and washed with PBS. Cells were spun down ( $300 \mathrm{~g}, 10$ minutes, RT) and cell pellets were resuspended in $50 \mu \mathrm{L}$ cold PBS containing 2 mM EDTA (Sigma-Aldrich) and 0.5\% BSA. FcR blocking reagent (Miltenyi Biotec $\mathrm{GmbH}$, Germany) and antibody staining cocktail (Table 1) were added to the samples, which were then incubated at $4^{\circ} \mathrm{C}$ for 10 minutes. For intracellular staining, cells were first incubated with near IR live dead stain alone $\left(4^{\circ} \mathrm{C}\right.$ for 10 minutes) and then fixed with $2 \%$ paraformaldehyde (Sigma-Aldrich) in PBS $\left(4^{\circ} \mathrm{C}\right.$ for 20 minutes), washed with PBS $2 \mathrm{mM}$ EDTA $0.5 \%$ BSA, and permeabilized with $0.1 \%$ saponin (from Quillaja, SigmaAldrich) in PBS 2 mM EDTA 0.5\% BSA for 15 minutes at $4^{\circ} \mathrm{C}$. Staining of permeabilized cells was continued as described except for near IR live dead stain, using buffers containing $0.1 \%$ saponin. Samples were protected from light throughout all the remaining steps. Erythrocyte lysis solution $(150 \mathrm{mM}$ ammonium chloride, $\mathrm{NH}_{4} \mathrm{Cl}, 10 \mathrm{mM}$ potassium hydrogen carbonate $\mathrm{KHCO}_{3}$, and $100 \mu \mathrm{M}$ ethylenediaminetetraacetic acid EDTA, all from Sigma-Aldrich, were dissolved in distilled water; $\mathrm{pH}$ was adjusted to 7.27 and stored at $4^{\circ} \mathrm{C}$ ) was added to the samples, followed by incubation for 10 minutes on ice. Cells were centrifuged for 8 minutes at $4^{\circ} \mathrm{C}$ and resuspended in $\mathrm{PBS} / 2 \mathrm{mM}$ EDTA/0.5\% BSA, an aliquot of the cell suspension was mixed with $3 \%$ acetic acid/methylene blue (Stemcell Technologies Inc., Canada), and nucleated cells were counted using a hemocytometer (Carl Roth GmbH + Co. KG, Germany). Remaining samples were then resuspended with PBS and analyzed by flow cytometer. 


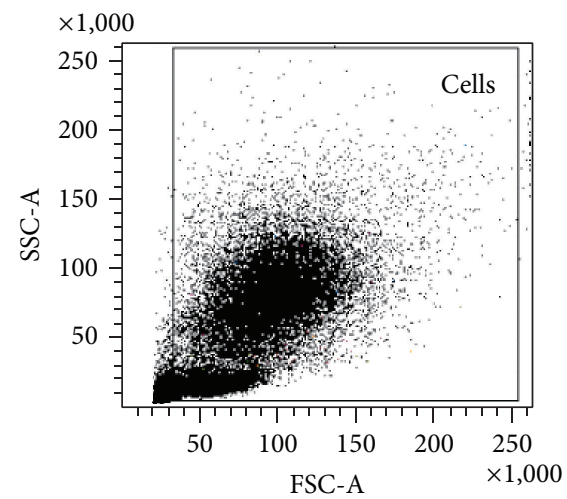

(a)

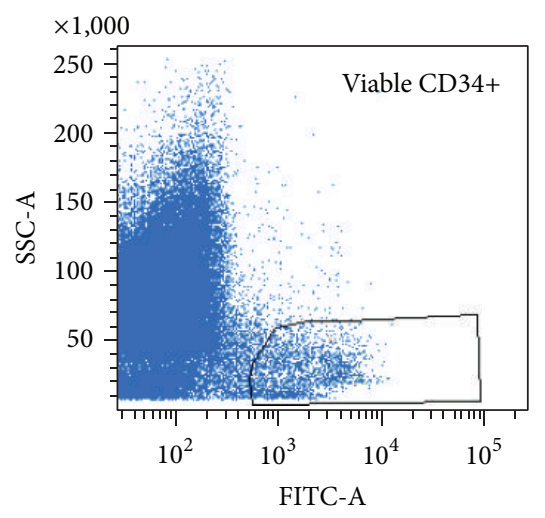

(c)

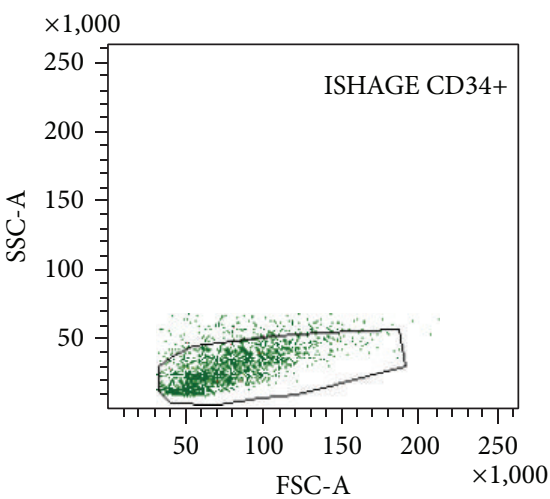

(e)

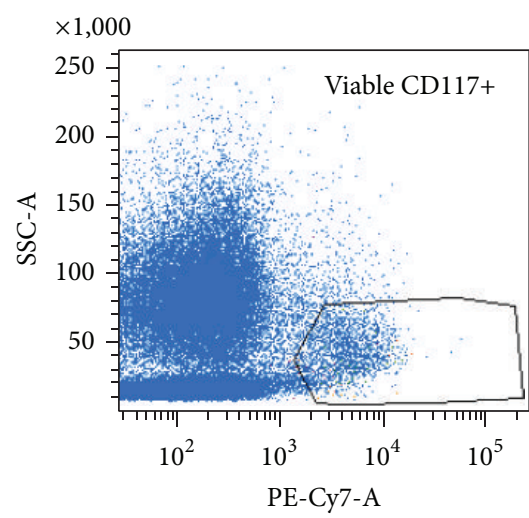

(g)

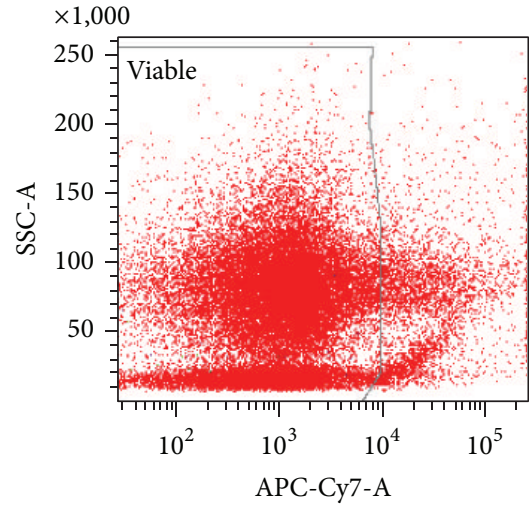

(b)

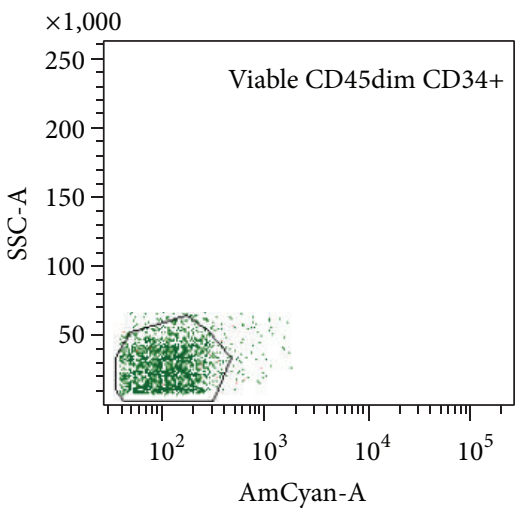

(d)

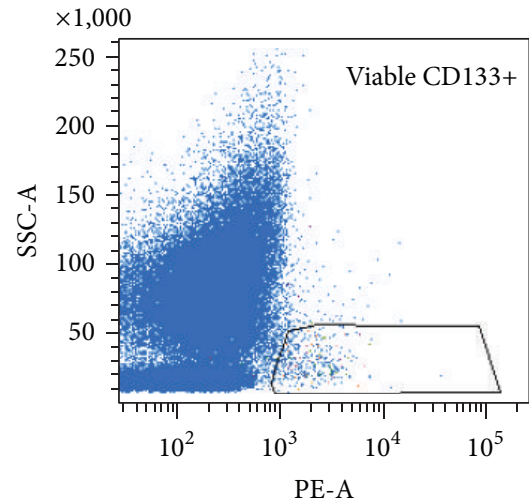

(f)

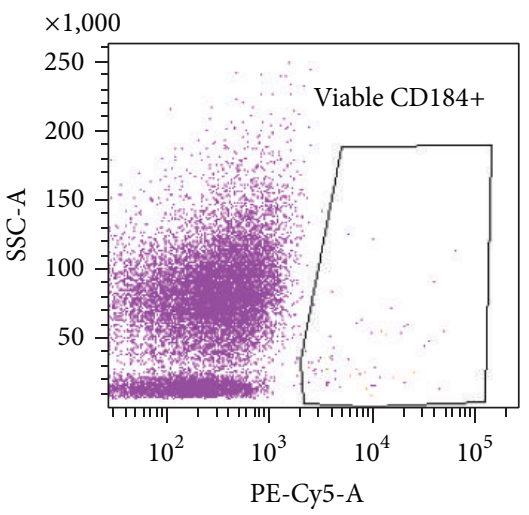

(h)

Figure 1: Continued. 


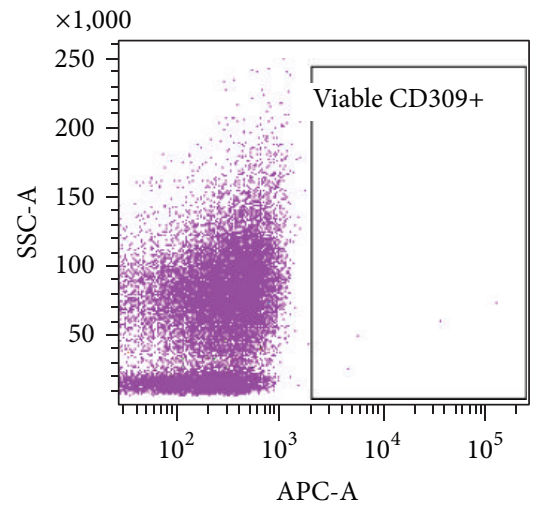

(i)

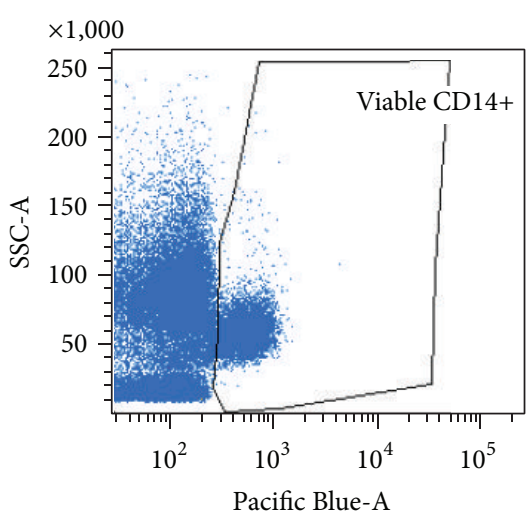

(j)

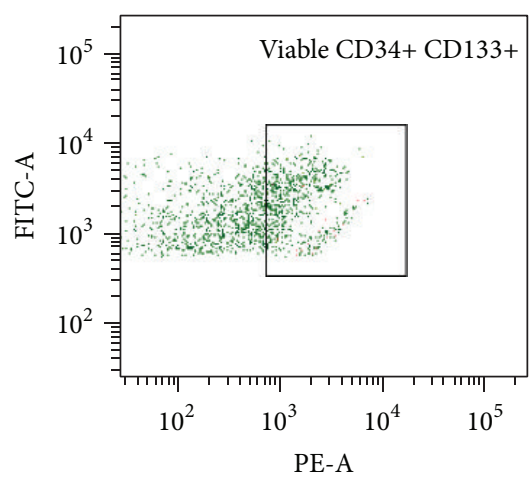

(k)

FIGURE 1: Flow cytometric gating strategy. Debris was excluded in a forward/side scatter (FSC/SSC) dot plot (a); viable cells were defined as cells with low/negative fluorescence in the APC-Cy7 channel (b). Hematopoietic stem cells were selected with an adapted ISHAGE gating strategy [25], exemplified for CD34 in (c)-(e): cells positive for CD34-FITC were gated (c); lymphocytes were excluded based on their high expression of CD45 (d). A FSC/SSC backgate was employed to select CD34+ cells with blast morphology (e). CD133+ and CD117+ HSCs were analysed accordingly ((f) and (g), resp.). CD184+ (CXCR4+), CD309+ (KDR+), and CD14+ cells were gated on viable cells ((h), (i), and (j), resp.). $\mathrm{CD} 34+\mathrm{CD} 133+$ double positive cell population was gated in a FITC/PE plot $(\mathrm{k})$. Subpopulations coexpressing further markers were selected from the ISHAGE-gated stem cell populations. CD34+ CD133+ CD117+ cells were analysed from ISHAGE-gated CD34+ CD133+ cells, and CD34+ CD117+ cells were analysed based on ISHAGE CD34+ cells.

FACS analysis was performed on BD FACS LSR-II (BD). Single stain samples for compensation were prepared using ArB and ArC bead kit (Life Technologies) according to manufacturer's instructions, as listed in Table 1. Bead single stainings were measured and automated calculation of compensation was performed using FACSDiva software (version 6.1.2, BD). Gating was established with fluorescence-minusone (FMO) controls. The Boolean gating strategy employed for evaluation of stem cell subpopulations is depicted in Figure 1.

2.4. Statistics. Data was evaluated using SigmaPlot (Systat Software Inc., USA). One-way ANOVA was performed for normally distributed variables; the method of Holm-Sidak was employed for post hoc testing. Nonnormally distributed continuous variables as well as variables with unequal variance were evaluated by Kruskal-Wallis one-way analysis of variance of ranks; multiple comparisons versus control group were performed as post hoc analyses according to Dunn's method. Data are presented as mean \pm SEM.

\section{Results and Discussion}

3.1. Donor Population. As all donors were cardiac surgery patients requiring sternotomy, samples included in the present study represent material of an aged patient population with considerable morbidity, typically presenting arterial hypertension and hypercholesterolemia. Therefore, conclusions drawn from our analyses may not be directly transferable to cell products derived from young, healthy donors. In contrast, the donor population is fairly representative for potential recipients of cell products for cardiac regeneration. While the donor population was heterogeneous
TABLE 2: Bone marrow donor characteristics.

\begin{tabular}{lc}
\hline Donor number & 26 \\
Proportion of male donors & $88.5 \%$ \\
Mean donor age & $64.2($ range $40-85)$ y \\
\hline
\end{tabular}

in terms of age, donor gender was predominantly male (Table 2).

3.2. Composition of Freshly Isolated BM-TNC. BM-TNC isolated by Res-Q 60 BMC System included all mature hematopoietic cell populations as well as stem and progenitor cells. Flow cytometric analysis of fresh BM-TNC is included in Figure 3.

Stem and progenitor cell populations were defined by their markers CD117, CD34, and CD133 as well as SDF-1 receptor CD184 (CXCR4). CD14, expressed by monocytes, served as a control marker for mature cells. CD14 was expressed on $4.03 \pm 0.37 \%$ of viable cells, a value within the expected range, as compared to monocyte concentrations described in the literature $(6.3 \pm 3.3 \%$ of leukocytes in bone marrow of healthy donors [26], 4.10\% of MNC in donor bone marrow grafts [27]). A minor fraction of cells expressed CD184 (14.56 $\pm 2.23 \%$ of viable cells), much less than that reported by Dotsenko et al. [28]. CD309 positive cells were very infrequent and could not be analysed reliably. CD309 was therefore excluded from marker evaluation. The most frequent stem cell population was CD117+ $(1.16 \pm 0.09 \%$ of viable cells), followed by CD34+ as the most common marker in flow cytometric stem cell analysis $(0.85 \pm 0.07 \%$ of viable cells). In comparison to previous studies, we found lower overall numbers of stem cells [26, 28-32]. Several 


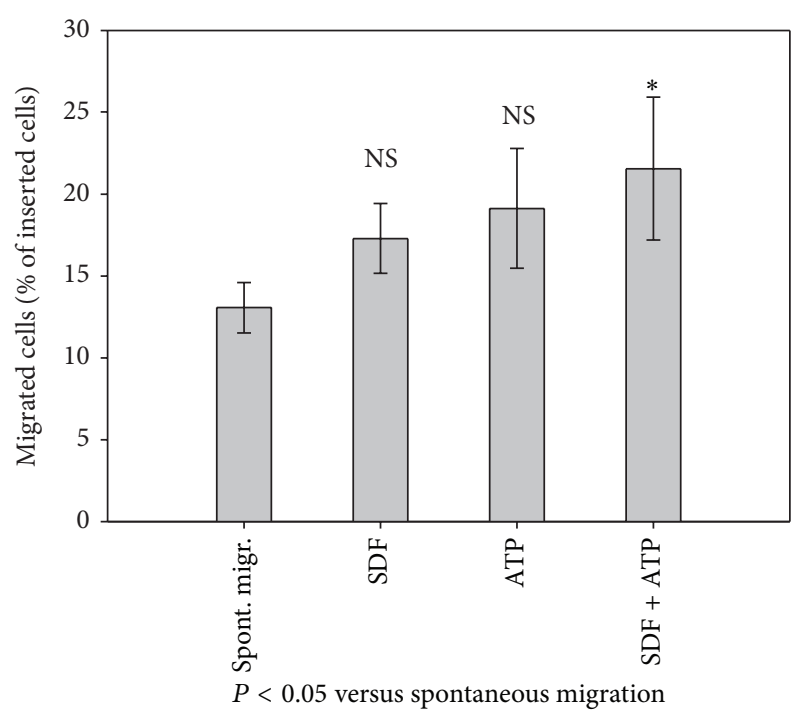

FIGURE 2: BM-TNCs migrated significantly towards SDF-1 + ATP. BM-TNCs were subjected to $100 \mathrm{ng} / \mathrm{mL}$ SDF-1 and/or $100 \mu \mathrm{M}$ ATP as migratory stimulant in a Boyden chamber for $24 \mathrm{~h}$; medium was employed to estimate spontaneous migration in absence of any migratory stimuli. Migrated BM-TNCs were retrieved from the lower chamber and counted in a hemocytometer, $n \geq 4$.

factors may account for this discrepancy: the individual bone marrow source may influence stem cell frequencies, as sternal bone marrow aspirates may be more diluted with peripheral blood than the iliac crest aspirates used by Tendera et al. [30] or Theilgaard-Mönch et al. [29]; Dor et al. [32] found 5.1\% CD117+ and 3.6\% CD34+ cells in human bone marrow derived from a single deceased human donor. Age and morbidity of the donor population may influence stem cell number, although this may not explain the difference to the study of Dotsenko et al. [28], which was comparable to our own study in terms of donor collective as well as bone marrow source. Differences in cell isolation procedure may influence the proportions of specific cell types; the gating strategy we employ is more restrictive than Dotsenko et al.'s due to multiple backgates and, as a result, may lead to lower stem cell numbers. In all multicolor flow cytometry analyses, spreading of populations occurs even in properly compensated samples and may lead to underestimation of target populations [33]. It is plausible that spreading may be more pronounced in the 8-fold staining we employed than in the commonly used 4-fold ISHAGE staining.

Stem cell populations overlapped considerably (Table 3). Again, our findings differed from Tendera et al. as well as Dotsenko et al.; notably, CD184+ cell proportion in CD34+ cells was considerably lower in our study compared to these and other studies [34-36].

3.3. Migration of BM-TNC. Total BM-TNC migrated significantly only towards a combination of SDF-1 and ATP, although a trend of migration towards either SDF-1 or ATP alone was detectable (Figure 2). This is a discrepancy compared to the findings of Seeger et al., who reported a $50 \%$ increase of BM-TNC invasion by $100 \mathrm{ng} / \mathrm{mL}$ SDF1 [37]. However, assay parameters differed notably between Seeger's and our experiments (cell isolation procedure, larger pore size, and Matrigel coating of Boyden chamber). Yet, the positive impact of ATP on SDF-1-triggered migration is in accord with the work of Ratajczak et al. [38].

As a sizable number of cells migrated spontaneously in the absence of any migratory stimulus, that is, via spontaneous migration, we performed flow cytometric analysis of these cells and compared their marker expression profile to those of freshly isolated BM-TNC as well as BM-TNC cultivated in assay medium ("incubation control") (Figure 3). Whereas cultivation for 24 hours did not affect expression of any of the examined markers significantly, the spontaneous migration group displayed an unanticipated change in the expression pattern. All included stem cell populations as well as subpopulations were diminished compared to both fresh and cultivated BM-TNCs. The CD184+ proportion was reduced significantly in cells after spontaneous migration as compared to cultivated BM-TNC. The fraction of CD184+ cells tended to increase with cultivation; however, this trend was not significant, possibly due to the large variability of expression for this marker (Figure 3(a)).

These findings may be explained by two separate effects:

(1) stem cell motility might be lower than motility of mature cells in the absence of specific stimuli;

(2) spontaneous migration and/or transmigration through a porous membrane might cause a reduction in stem cell marker expression (e.g., by internalization). Therefore, migrated stem cells would no longer be detected as such by flow cytometric analysis.

For CD117, CD34, and CD133, internalization in response to specific triggers has been described [39-41]. The triggers, however, vary conspicuously, and no reports of internalization of these markers through migration have yet been published.

In order to clarify the relevant mechanism for our finding, we performed intracellular staining after incubation and spontaneous migration. Again, stem cell markers were detected on or in fewer cells after spontaneous migration, suggesting that migrated stem cells were not concealed by marker internalization in our previous experiment (Figure 4). A level of significance was only reached for spontaneously migrated cells in comparison to fresh BM-TNC; however, a clear trend towards fewer stem cells was displayed compared to the incubation control.

Therefore, lower motility of stem cells seems the most probable explanation of our results. In fact, Shin et al. found that, due to their lower lamin A:B stoichiometry, stem/progenitor cells possess more rigid nuclei than mature blood cells, which hinders their capacity to deform and migrate through $3 \mu \mathrm{m}$ pores [42]. This accords well with our present data and may account for the low numbers of stem cells in the spontaneous migration fraction.

Presence of SDF-1 or ATP altered the composition of migrated cells substantially (Figure 5). After migration along an SDF-1 or a combined SDF-1 and ATP gradient, CD34+ 


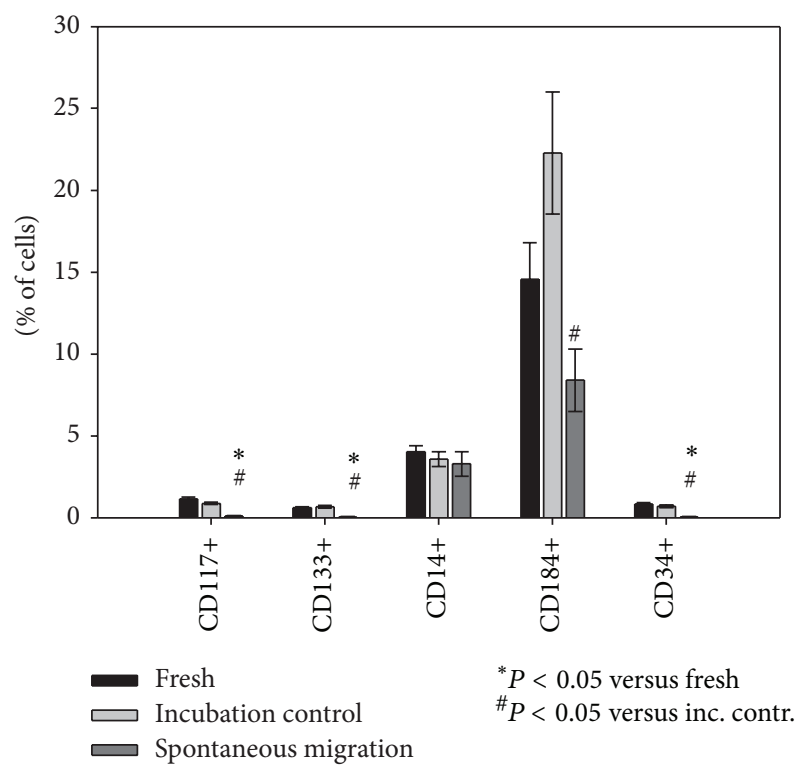

(a)

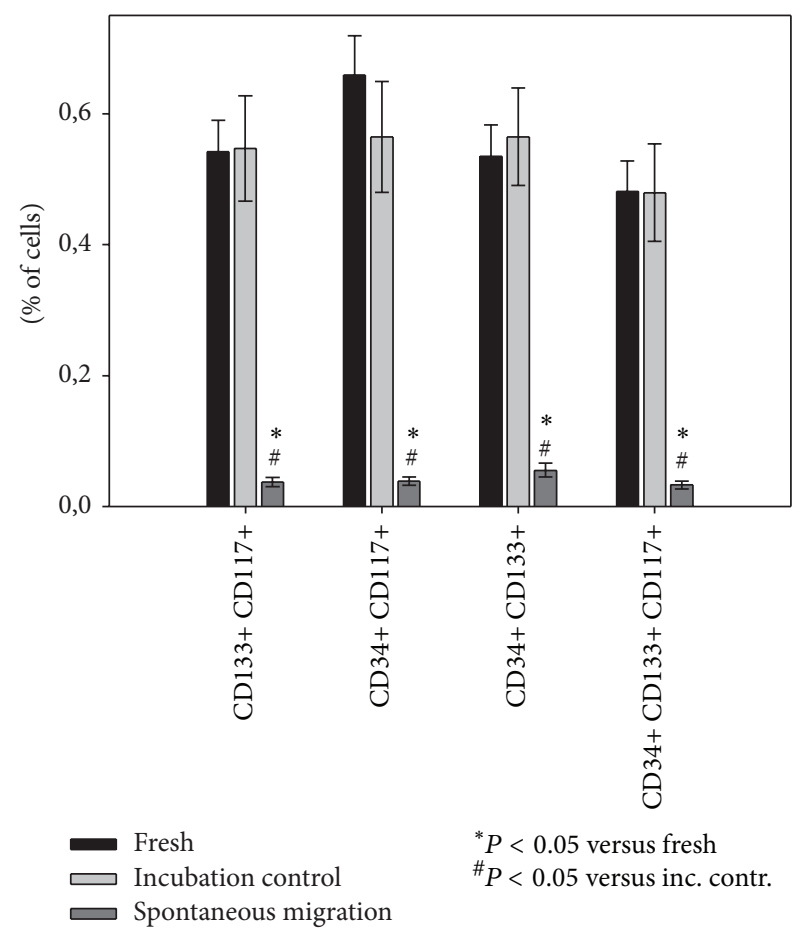

(b)

FIGURE 3: Stem cell populations were diminished significantly after spontaneous migration. Multicolor flow cytometric analyses were performed on BM-TNC after isolation ("fresh"), after cultivation ("incubation control"), or on BM-TNC retrieved from lower Boyden chamber after cultivation for $24 \mathrm{~h}$ ("spontaneous migration"). Cell populations (a) and stem cell subpopulations (b) were evaluated as shown in Figure 1. $\mathrm{CD} 34+, \mathrm{CD} 133+$, and CD117+ cells formed significantly lower percentages of BM-TNC which had undergone spontaneous migration (a). The effect was even more pronounced for populations expressing multiple stem cell markers (b). Incubation had no influence on CD34+, CD133+, and CD117+ cells or on their subpopulations but led to an increase in CD184+ cells, $n=10$.

TABLE 3: Stem cell population overlap in BM-TNC.

\begin{tabular}{lcccc}
\hline Subpopulation & \% of CD34+ cells & \% of CD133+ cells & \% of CD117+ cells & \% of CD34+ CD133+ cells \\
\hline CD34+ CD133+ & $62.32 \pm 2.39$ & $84.79 \pm 2.91$ & - & - \\
CD34+ CD133+ CD117+ & $55.64 \pm 2.43$ & $75.69 \pm 3.11$ & $41.21 \pm 2.60$ & $89.04 \pm 1.47$ \\
CD34+ CD117+ & $77.29 \pm 1.87$ & - & $56.80 \pm 3.11$ & - \\
CD133+ CD117+ & - & $86.08 \pm 1.72$ & $46.89 \pm 2.79$ & - \\
CD34+ CD184+ & $24.31 \pm 3.02$ & - & - & - \\
CD117+ CD184+ & - & - & $20.13 \pm 2.68$ & - \\
CD34+ CD133+ CD184+ & $11.65 \pm 1.81$ & $16.59 \pm 2.77$ & - & $19.39 \pm 3.06$ \\
\hline
\end{tabular}

stem cells were present in significantly higher proportion. A significant increase was detected by ANOVA for CD117+ and CD133+ cell percentages as well; however, post hoc analysis did not confirm this. Subpopulations expressing multiple stem cell markers were significantly augmented. In contrast, monocytes remained unaffected. Cell composition after migration towards ATP corresponded to that of the spontaneous migration fraction.

Despite the fact that CD184 is the receptor for SDF-1 and plays a fundamental role in stem cell homing along SDF1 gradients, no increase in CD184+ cells in the SDF-1 or SDF-1 + ATP-migrated fractions was detected. As Signoret et al. demonstrated, CD184 is internalized after binding of its ligand [43]. To verify whether receptor internalization took place during our experiment, we analyzed cells incubated with SDF-1/SDF-1 + ATP (Figure 6). A significant decrease in CD184 expression was indeed observed after incubation with SDF-1. Incubation with SDF-1 + ATP led to a noticeable, albeit not quite significant, decrease as well. More CD14+ cells were detected after incubation with ATP. A possible explanation for this finding could be ATP-triggered secretion of IL- $1 \beta$, a well-known inducer of CD14 $[44,45]$. No significant changes occurred in the other cell populations.

\section{Conclusion}

The present work gives an account of the migration potential of cell populations contained in a bone marrow-derived cell 


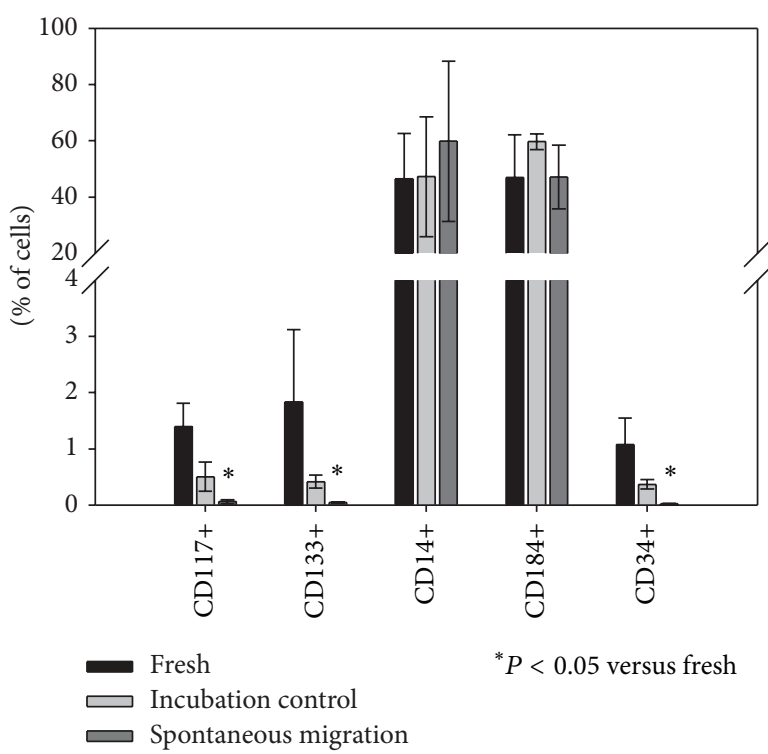

(a)

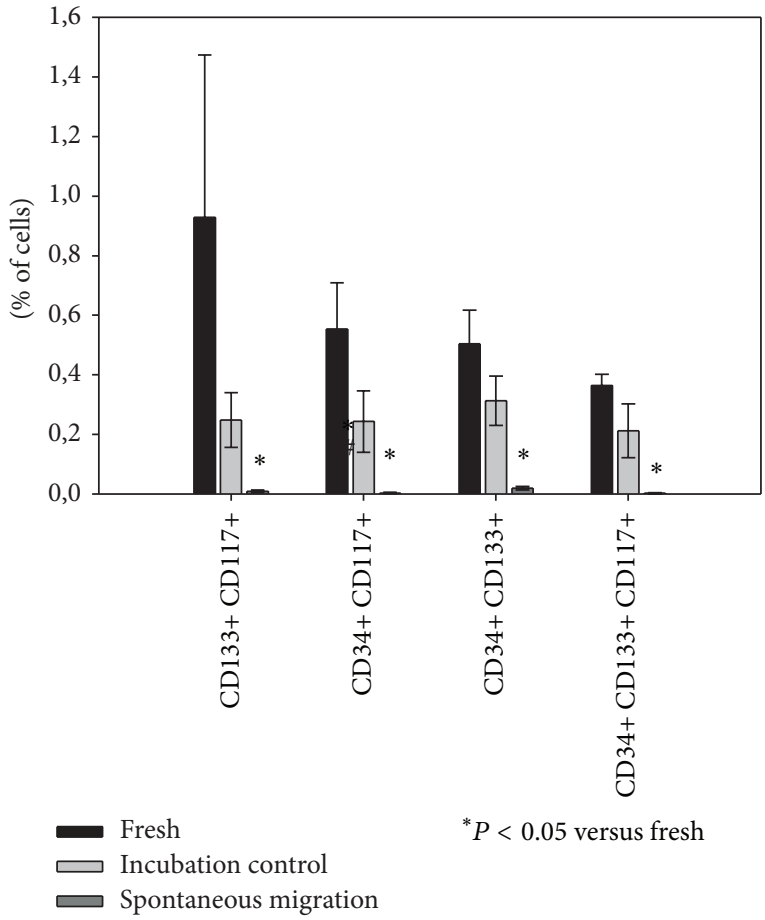

(b)

FIGURE 4: Diminished stem cell populations after spontaneous migration may not be explained by marker internalization. Intracellular multicolor flow cytometric analyses were performed on BM-TNC after isolation ("fresh"), after cultivation ("incubation control"), or on BM-TNC retrieved from lower Boyden chamber after cultivation for $24 \mathrm{~h}$ ("spontaneous migration"). Cell populations (a) and stem cell subpopulations (b) were evaluated as shown in Figure 1. After spontaneous migration, CD34+, CD133+, and CD117+ cells (a) as well as populations expressing multiple stem cell markers (b) formed lower percentages of BM-TNC, $n=3$.

product. The migratory stimuli employed, namely, stem cell chemokine SDF-1 and free nucleotide ATP, are both present in myocardial tissue after ischemic injury. To our knowledge, we are the first to give a comprehensive analysis of specific stem cell populations after in vitro migration towards these stimuli.

We found that total BM-TNCs migrated significantly towards SDF-1 and ATP, while migration towards SDF-1 alone did not reach the level of significance. It is conceivable that ATP may contribute to BM-TNC homing after transplantation. Differentiated hematopoietic cells as well as progenitors have been shown to express P2 nucleotide receptors [46] which may detect ATP and trigger diverse cellular reactions such as migration [47]. Considering plausible locations for ATP release in injured myocardium as well as cell populations migrating significantly towards ATP, however, ATP-triggered migration might not be responsible for regenerative effects of BM-TNC.

In cardiac regeneration, hibernating tissue regions with lowered metabolism despite continuing viability seem to profit most from cell transplantation [48]. Whereas ATP is set free to the intracellular space by necrotic cell death [49], total tissue ATP is decreased in hibernating myocardium $[50,51]$ and disruptive cardiomyocyte death is not typical for these areas. Considering ATP to be a migratory stimulus along with SDF-1, targeting of transplanted cells and physiological recruiting of cells directly from bone marrow might lead to cell presence in injured tissue with suboptimal susceptibility to be rescued.

Our analysis of cell populations migrating towards SDF1, ATP, or a combination of both showed that CD34+ stem cells as well as subpopulations expressing multiple stem cell markers displayed significant migration towards SDF-1 + ATP. The percentage of these populations, however, was also increased significantly in cells migrated towards SDF1 alone. The selective attraction of stem cell populations therefore relies on SDF-1, not on ATP. The increase of total migrating BM-TNC may be accounted for by neutrophils, which form the majority of leukocytes and are known to react to nucleotides as migratory stimuli [21]. Whereas neither the most active cell populations nor their exact mechanism of action has been completely clarified to date, it seems improbable that proinflammatory, short-living differentiated cells such as neutrophils would produce a beneficial effect in hibernating cardiac tissue.

CD184+ cell proportion was not changed by migration towards SDF-1, although CD184 is its main receptor. However, receptor downregulation may account for this finding, confirmed by the CD184+ cell decrease we detected after incubation with SDF-1.

Stem cells displayed lower spontaneous migration than differentiated cells as shown by extra- and intracellular 


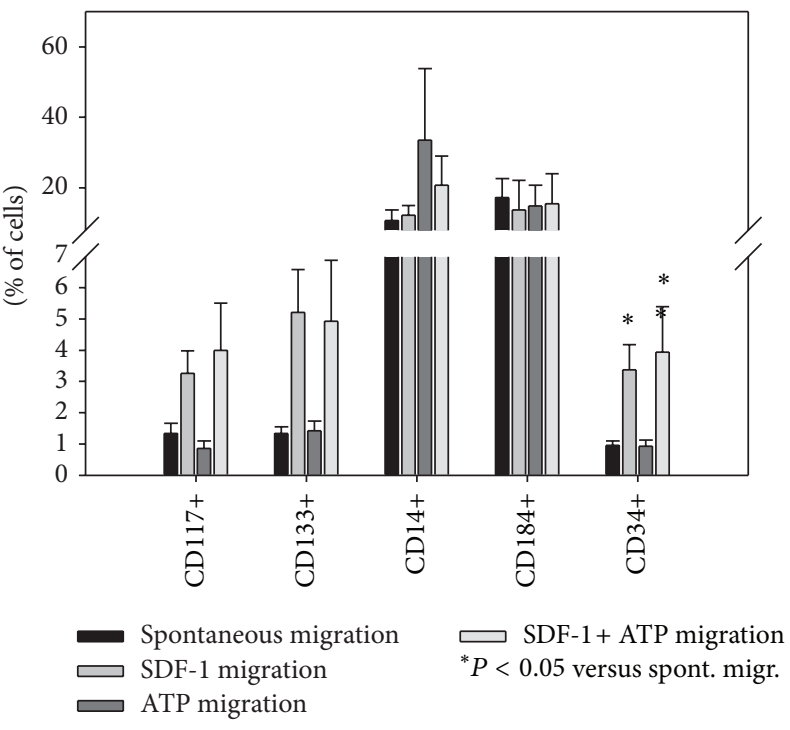

(a)

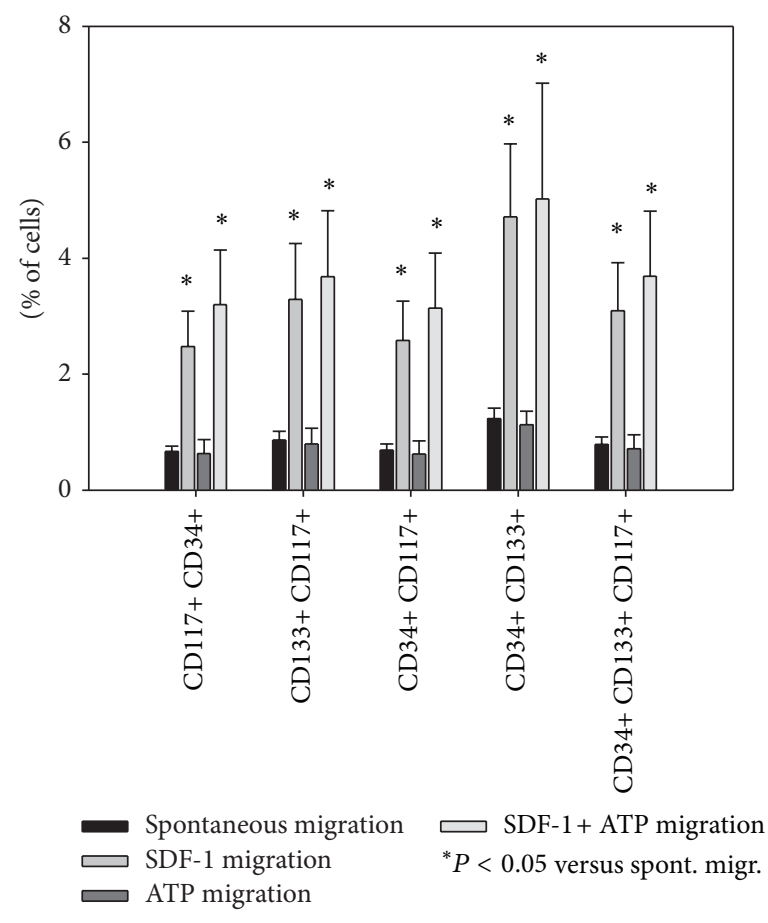

(b)

FIGURE 5: CD34+ stem cells as well as subpopulations positive for multiple stem cell markers migrated significantly towards SDF-1 + ATP. After in vitro migration for $24 \mathrm{~h}$ towards medium ("spontaneous migration"), $100 \mathrm{ng} / \mathrm{mL}$ SDF-1 ("SDF-1 migration"), $100 \mu \mathrm{M}$ ATP ("ATP migration"), or a combination of both ("SDF-1 + ATP migration"), BM-TNCs were analysed by flow cytometry. Cell populations (a) and stem cell subpopulations (b) were evaluated as described in Figure 1. CD34+ cell number was significantly elevated in BM-TNCs after migration towards SDF-1 or SDF-1 + ATP (a); subpopulations expressing multiple stem cell markers also displayed higher concentrations in SDF-1 or SDF-1 + ATP migrated fraction (b), $n \geq 4$.

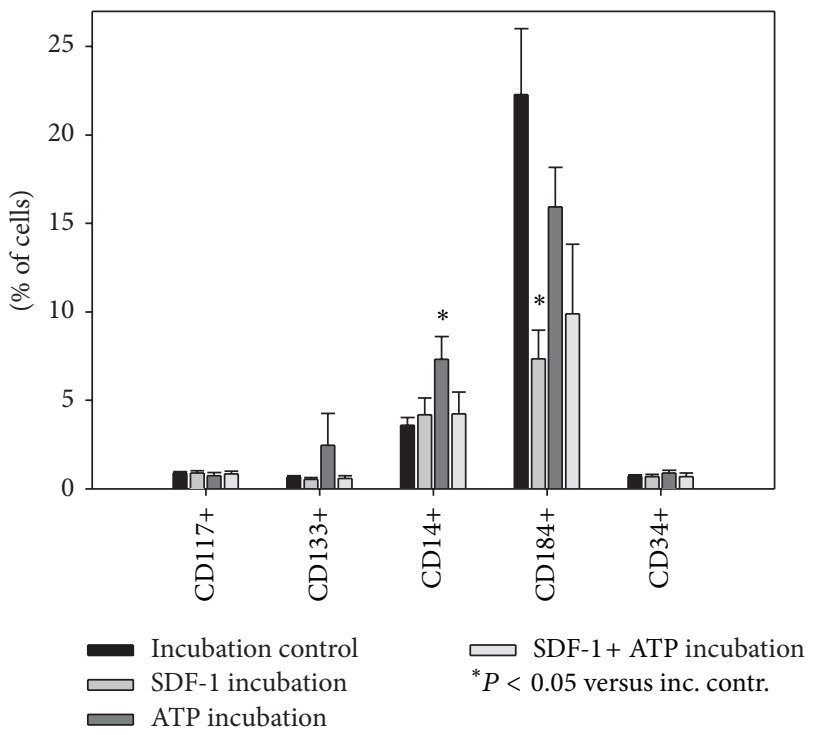

FIGURE 6: The proportion of CD184+ cells was lower after incubation with SDF-1. Following incubation for $24 \mathrm{~h}$ with medium ("incubation control"), $100 \mathrm{ng} / \mathrm{mL}$ SDF-1 ("SDF-1 incubation"), $100 \mu \mathrm{M}$ ATP ("ATP incubation"), or a combination of both ("SDF-1 + ATP incubation"), BM-TNCs were analysed by flow cytometry. Cell populations were evaluated as described in Figure 1. CD184+ cell proportion decreased significantly after incubation with SDF-1, while other populations were not affected. CD14+ cell population was increased after incubation with ATP, $n \geq 4$. marker analysis; this finding corresponds to the report of Shin et al. that stem cell nuclei are more rigid and less likely to be deformed, thereby hindering cellular migration through pores. Whereas the extent of stem cell transmigration may thus be limited, specificity of stem cell recruitment into injured tissue is likely enhanced.

Our findings emphasize the complexity of cell migration in presence of different stimuli. Populations displaying elevated migratory potential, such as cells coexpressing multiple stem cell markers, may be especially promising for therapy or as biomarkers. Whether these populations are also highly active by paracrine secretion or differentiation or via stimulation of cardiomyocytes and resident cardiac stem cells remains to be tested. Culture expansion or in vitro generation of these rare populations may serve to provide cells for regenerative targeting in the future. Application of ATP in addition to SDF-1, on the other hand, did not enhance stem cell-specific migration and its clinical use is not recommendable based on our present work. Ultimately, the reduced spontaneous migration of stem cells compared to differentiated cells may be made use of innovative methods for gentle, label-free stem cell purification.

\section{Conflict of Interests}

The authors declare that there is no conflict of interests regarding the publication of this paper. 


\section{Acknowledgments}

The authors would like to thank their project partner, Henry Kuper/Recuperate Medical, for providing them with the ResQ 60 BMC System. Furthermore, they are very grateful for the assistance of their collaborators Sandra Bubritzki and Madeleine Bartsch who performed multiple isolations of BMTNC and would like to thank Anita Tölk and Margit Fritsche for providing excellent technical assistance.

\section{References}

[1] T. Asahara, H. Masuda, T. Takahashi et al., "Bone marrow origin of endothelial progenitor cells responsible for postnatal vasculogenesis in physiological and pathological neovascularization," Circulation Research, vol. 85, no. 3, pp. 221-228, 1999.

[2] D. Orlic, J. Kajstura, S. Chimenti et al., "Bone marrow cells regenerate infarcted myocardium," Nature, vol. 410, no. 6829, pp. 701-705, 2001.

[3] H. Kamihata, H. Matsubara, T. Nishiue et al., "Implantation of bone marrow mononuclear cells into ischemic myocardium enhances collateral perfusion and regional function via side supply of angioblasts, angiogenic ligands, and cytokines," Circulation, vol. 104, no. 9, pp. 1046-1052, 2001.

[4] T.-S. Li, K. Hamano, M. Nishida et al., "CD117 ${ }^{+}$stem cells play a key role in therapeutic angiogenesis induced by bone marrow cell implantation," American Journal of Physiology: Heart and Circulatory Physiology, vol. 285, no. 3, pp. H931-H937, 2003.

[5] C. Stamm, B. Westphal, H.-D. Kleine et al., "Autologous bonemarrow stem-cell transplantation for myocardial regeneration," The Lancet, vol. 361, no. 9351, pp. 45-46, 2003.

[6] T. Dill, V. Schächinger, A. Rolf et al., "Intracoronary administration of bone marrow-derived progenitor cells improves left ventricular function in patients at risk for adverse remodeling after acute ST-segment elevation myocardial infarction: results of the reinfusion of enriched progenitor cells and infarct remodeling in acute myocardial infarction study (REPAIRAMI) cardiac magnetic resonance imaging substudy," American Heart Journal, vol. 157, no. 3, pp. 541-547, 2009.

[7] P. Donndorf, G. Kundt, A. Kaminski et al., "Intramyocardial bone marrow stem cell transplantation during coronary artery bypass surgery: a meta-analysis," The Journal of Thoracic and Cardiovascular Surgery, vol. 142, no. 4, pp. 911-920, 2011.

[8] K. A. Jackson, S. M. Majka, H. Wang et al., "Regeneration of ischemic cardiac muscle and vascular endothelium by adult stem cells," Journal of Clinical Investigation, vol. 107, no. 11, pp. 1395-1402, 2001.

[9] A. Peled, I. Petit, O. Kollet et al., "Dependence of human stem cell engraftment and repopulation of NOD/SCID mice on CXCR4," Science, vol. 283, no. 5403, pp. 845-848, 1999.

[10] M. Kucia, K. Jankowski, R. Reca et al., "CXCR4-SDF-1 signalling, locomotion, chemotaxis and adhesion," Journal of Molecular Histology, vol. 35, no. 3, pp. 233-245, 2004.

[11] D. P. J. Kavanagh and N. Kalia, "Hematopoietic stem cell homing to injured tissues," Stem Cell Reviews and Reports, vol. 7, no. 3, pp. 672-682, 2011.

[12] A. T. Askari, S. Unzek, Z. B. Popovic et al., "Effect of stromalcell-derived factor 1 on stem-cell homing and tissue regeneration in ischaemic cardiomyopathy," The Lancet, vol. 362, no. 9385, pp. 697-703, 2003.

[13] M. Rothmund, K.-W. Jauch, and H. Bauer, "Bedeutung von stromal cell derived factor-1 (SDF-1) für das "homing" von
Stammzellen,' in Chirurgisches Forum, vol. 34, pp. 383-384, Springer, Berlin, Germany, 2005.

[14] J. D. Abbott, Y. Huang, D. Liu, R. Hickey, D. S. Krause, and F. J. Giordano, "Stromal cell-derived factor- $1 \alpha$ plays a critical role in stem cell recruitment to the heart after myocardial infarction but is not sufficient to induce homing in the absence of injury," Circulation, vol. 110, no. 21, pp. 3300-3305, 2004.

[15] T. Asahara, T. Takahashi, H. Masuda et al., "VEGF contributes to postnatal neovascularization by mobilizing bone marrowderived endothelial progenitor cells," EMBO Journal, vol. 18, no. 14, pp. 3964-3972, 1999.

[16] N. G. Frangogiannis, "The immune system and cardiac repair," Pharmacological Research, vol. 58, no. 2, pp. 88-111, 2008.

[17] T. Forrester and C. A. Williams, "Release of adenosine triphosphate from isolated adult heart cells in response to hypoxia," The Journal of Physiology, vol. 268, no. 2, pp. 371-390, 1977.

[18] T. C. Clarke, O. J. S. Williams, P. E. M. Martin, and W. H. Evans, "ATP release by cardiac myocytes in a simulated ischaemia model: inhibition by a connexin mimetic and enhancement by an antiarrhythmic peptide," European Journal of Pharmacology, vol. 605, no. 1-3, pp. 9-14, 2009.

[19] D. Erlinge, J. Harnek, C. van Heusden, G. Olivecrona, S. Jern, and E. Lazarowski, "Uridine triphosphate (UTP) is released during cardiac ischemia," International Journal of Cardiology, vol. 100, no. 3, pp. 427-433, 2005.

[20] R. Corriden and P. A. Insel, "New insights regarding the regulation of chemotaxis by nucleotides, adenosine, and their receptors," Purinergic Signalling, vol. 8, no. 3, pp. 587-598, 2012.

[21] Y. Chen, R. Corriden, Y. Inoue et al., "ATP release guides neutrophil chemotaxis via P2Y2 and A3 receptors," Science, vol. 314, no. 5806, pp. 1792-1795, 2006.

[22] E. Kaczmarek, L. Erb, K. Koziak et al., "Modulation of endothelial cell migration by extracellular nucleotides. Involvement of focal adhesion kinase and phosphatidylinositol 3-kinasemediated pathways," Thrombosis and Haemostasis, vol. 93, no. 4, pp. 735-742, 2005.

[23] L. Rossi, R. Manfredini, F. Bertolini et al., "The extracellular nucleotide UTP is a potent inducer of hematopoietic stem cell migration," Blood, vol. 109, no. 2, pp. 533-542, 2007.

[24] C. Nesselmann, A. Kaminski, and G. Steinhoff, "Cardiac stem cell therapy," Herz, vol. 36, no. 2, pp. 121-134, 2011.

[25] D. R. Sutherland, L. Anderson, M. Keeney, R. Nayar, and I. Chin-Yee, "The ISHAGE guidelines for CD34+ cell determination by flow cytometry," Journal of Hematotherapy \& Stem Cell Research, vol. 5, no. 3, pp. 213-226, 1996.

[26] R.-K. Zhong, A. D. Donnenberg, J. Rubin, and E. D. Ball, "Differential effect of 4-hydroperoxycyclophospamide and antimyeloid monoclonal antibodies on $\mathrm{T}$ and natural killer cells during bone marrow purging," Blood, vol. 83, no. 8, pp. 23452351, 1994.

[27] L.-P. Xu, X.-H. Luo, Y.-J. Chang et al., "High CD4/CD8 ratio in allografts predicts adverse outcomes in unmanipulated HLAmismatched/haploidentical hematopoietic stem cell transplantation for chronic myeloid leukemia," Annals of Hematology, vol. 88 , no. 10, pp. 1015-1024, 2009.

[28] O. Dotsenko, Q. Xiao, Q. Xu, and M. Jahangiri, "Bone marrow resident and circulating progenitor cells in patients undergoing cardiac surgery," Annals of Thoracic Surgery, vol. 90, no. 6, pp. 1944-1951, 2010.

[29] K. Theilgaard-Mönch, K. Raaschou-Jensen, H. Palm et al., "Flow cytometric assessment of lymphocyte subsets, lymphoid 
progenitors, and hematopoietic stem cells in allogeneic stem cell grafts," Bone Marrow Transplantation, vol. 28, no. 11, pp. 10731082, 2001.

[30] M. Tendera, W. Wojakowski, W. Ruyłło et al., "Intracoronary infusion of bone marrow-derived selected CD34 +CXCR4+ cells and non-selected mononuclear cells in patients with acute STEMI and reduced left ventricular ejection fraction: results of randomized, multicentre Myocardial Regeneration by Intracoronary Infusion of Selected Population of Stem Cells in Acute Myocardial Infarction (REGENT) Trial," European Heart Journal, vol. 30, no. 11, pp. 1313-1321, 2009.

[31] E. A. de Wynter, D. Buck, C. Hart et al., "CD34 ${ }^{+} \mathrm{AC} 133^{+}$cells isolated from cord blood are highly enriched in long-term culture-initiating cells, NOD/SCID-repopulating cells and dendritic cell progenitors," Stem Cells, vol. 16, no. 6, pp. 387-396, 1998.

[32] F. J. M. F. Dor, M. L. Ramirez, K. Parmar et al., "Primitive hematopoietic cell populations reside in the spleen: Studies in the pig, baboon, and human," Experimental Hematology, vol. 34, no. 11, pp. 1573-1582, 2006.

[33] M. Roederer, "Spectral compensation for flow cytometry: visualization artifacts, limitations, and caveats," Cytometry, vol. 45, no. 3, pp. 194-205, 2001.

[34] A. Aiuti, L. Turchetto, M. Cota et al., "Human $\mathrm{CD} 34^{+}$cells express CXCR4 and its ligand stromal cell-derived factor-1. Implications for infection by T-cell tropic human immunodeficiency virus," Blood, vol. 94, no. 1, pp. 62-73, 1999.

[35] M. Dabusti, E. Ferrazzi, G. Castoldi et al., "CXCR-4 expression on bone marrow $\mathrm{CD} 34^{+}$cells prior to mobilization can predict mobilization adequacy in patients with hematologic malignancies," Journal of Hematotherapy and Stem Cell Research, vol. 12, no. 4, pp. 425-434, 2003.

[36] C. Herrera, J. Sanchez, A. Torres, A. Pascual, A. Rueda, and M. A. Alvarez, "Pattern of expression of CXCR4 and adhesion molecules by human $\mathrm{CD} 34^{+}$cells from different sources: role in homing efficiency in NOD/SCID mice," Haematologica, vol. 89, no. 9, pp. 1037-1045, 2004.

[37] F. H. Seeger, T. Tonn, N. Krzossok, A. M. Zeiher, and S. Dimmeler, "Cell isolation procedures matter: a comparison of different isolation protocols of bone marrow mononuclear cells used for cell therapy in patients with acute myocardial infarction," European Heart Journal, vol. 28, no. 6, pp. 766-772, 2007.

[38] M. Z. Ratajczak, C. Kim, A. Janowska-Wieczorek, and J. Ratajczak, "The expanding family of bone marrow homing factors for hematopoietic stem cells: stromal derived factor 1 is not the only player in the game," The Scientific World Journal, vol. 2012, Article ID 758512, 11 pages, 2012.

[39] L. Rönnstrand, "Signal transduction via the stem cell factor receptor/c-Kit," Cellular and Molecular Life Sciences, vol. 61, no. 19-20, pp. 2535-2548, 2004.

[40] N. Bauer, A.-V. Fonseca, M. Florek et al., "New insights into the cell biology of hematopoietic progenitors by studying prominin-1 (CD133)," Cells Tissues Organs, vol. 188, no. 1-2, pp. 127-138, 2008.

[41] J. Krauter, M. Hartl, L. Hambach et al., "Receptor-mediated endocytosis of CD34 on hematopoietic cells after stimulation with the monoclonal antibody anti-HPCA-1," Journal of Hematotherapy and Stem Cell Research, vol. 10, no. 6, pp. 863-871, 2001.

[42] J.-W. Shin, K. R. Spinler, J. Swift, J. A. Chasis, N. Mohandas, and D. E. Discher, "Lamins regulate cell trafficking and lineage maturation of adult human hematopoietic cells," Proceedings of the National Academy of Sciences of the United States of America, vol. 110, no. 47, pp. 18892-18897, 2013.

[43] N. Signoret, J. Oldridge, A. Pelchen-Matthews et al., "Phorbol esters and SDF-1 induce rapid endocytosis and down modulation of the chemokine receptor CXCR4," The Journal of Cell Biology, vol. 139, no. 3, pp. 651-664, 1997.

[44] N. Riteau, L. Baron, B. Villeret et al., "ATP release and purinergic signaling: a common pathway for particle-mediated inflammasome activation," Cell Death \& Disease, vol. 3, no. 10, article e403, 2012.

[45] H. W. L. Ziegler-Heitbrock and R. J. Ulevitch, "CD14: cell surface receptor and differentiation marker," Immunology Today, vol. 14, no. 3, pp. 121-125, 1993.

[46] L. Wang, S. E. W. Jacobsen, A. Bengtsson, and D. Erlinge, "P2 receptor mRNA expression profiles in human lymphocytes, monocytes and CD34+ stem and progenitor cells," BMC Immunology, vol. 5, article 16, 2004.

[47] C. Agresti, M. E. Meomartini, S. Amadio et al., "Metabotropic P2 receptor activation regulates oligodendrocyte progenitor migration and development," Glia, vol. 50, no. 2, pp. 132-144, 2005.

[48] A. Blatt, G. Cotter, M. Leitman et al., "Intracoronary administration of autologous bone marrow mononuclear cells after induction of short ischemia is safe and may improve hibernation and ischemia in patients with ischemic cardiomyopathy," American Heart Journal, vol. 150, no. 5, pp. 986.e1-986.e7, 2005.

[49] H. J. Zeh III and M. T. Lotze, "Addicted to death: invasive cancer and the immune response to unscheduled cell death," Journal of Immunotherapy, vol. 28, no. 1, pp. 1-9, 2005.

[50] G. Heusch and R. Schulz, "Hibernating myocardium: a review," Journal of Molecular and Cellular Cardiology, vol. 28, no. 12, pp. 2359-2372, 1996.

[51] R. Ferrari, C. Ceconi, S. Curello, M. Benigno, G. la Canna, and O. Visioli, "Left ventricular dysfunction due to the new ischemic outcomes: stunning and hibernation," Journal of Cardiovascular Pharmacology, vol. 28, supplement 1, pp. S18-S26, 1996. 


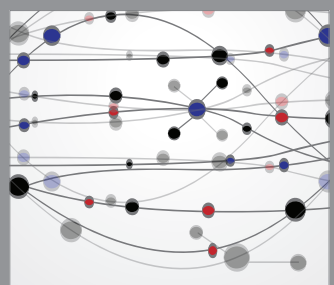

The Scientific World Journal
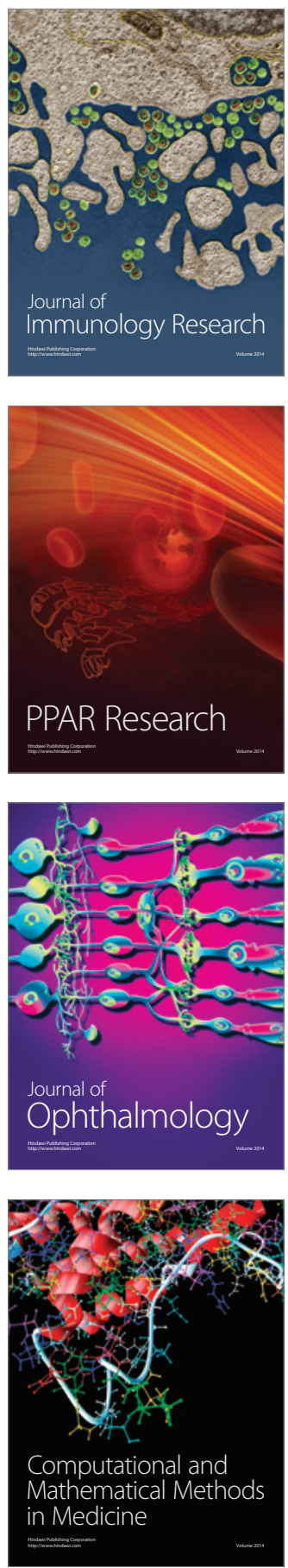

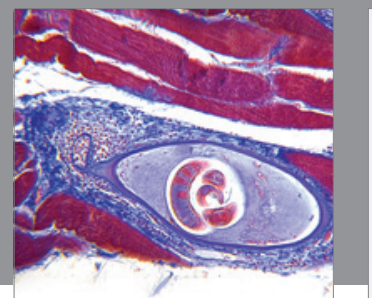

Gastroenterology

Research and Practice
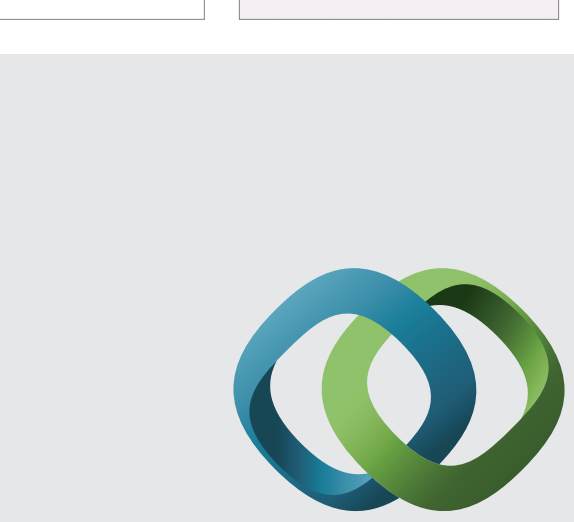

\section{Hindawi}

Submit your manuscripts at

http://www.hindawi.com
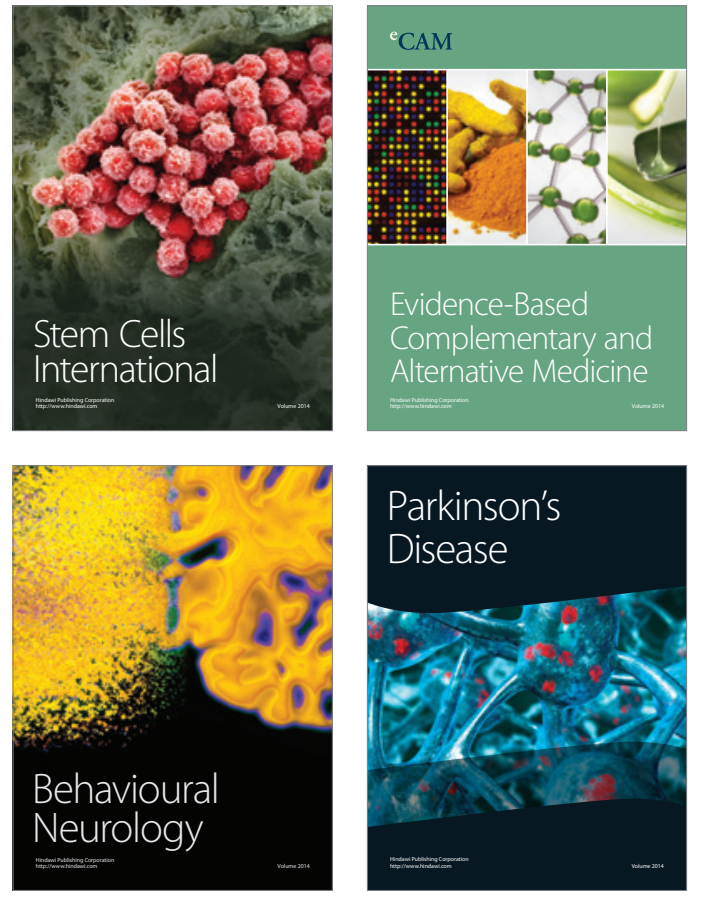
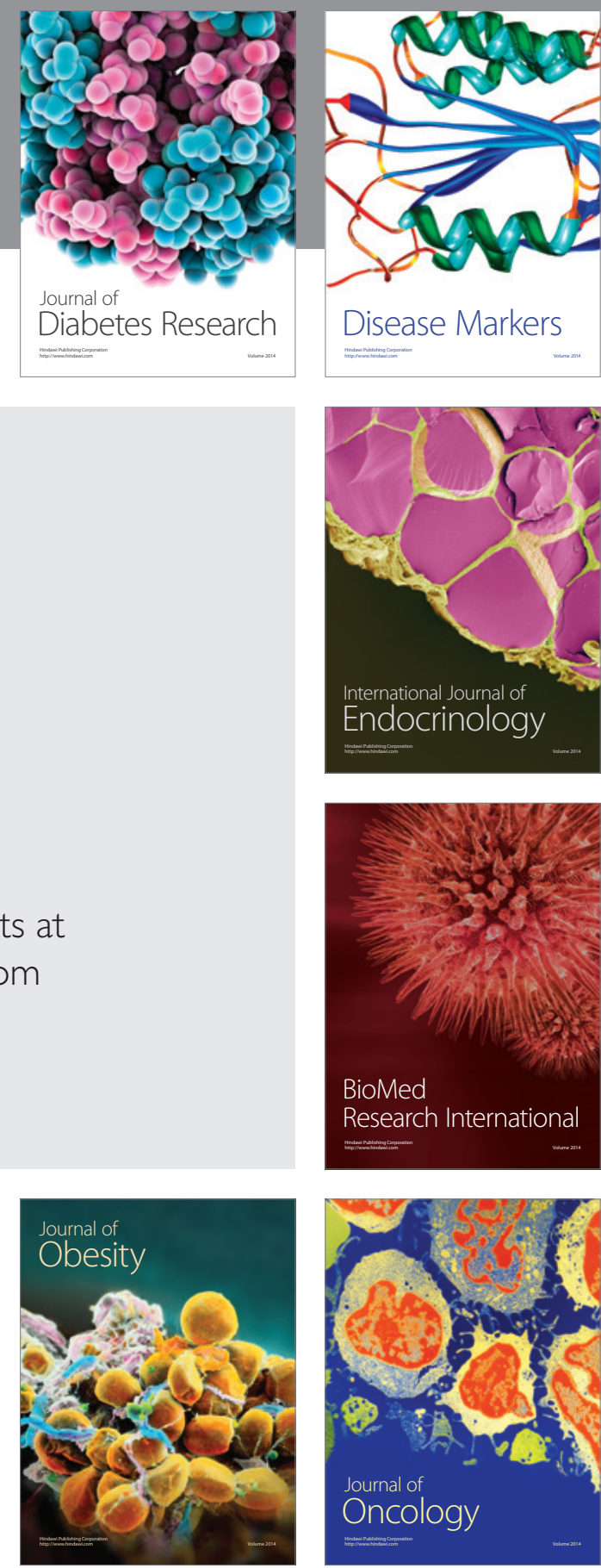

Disease Markers
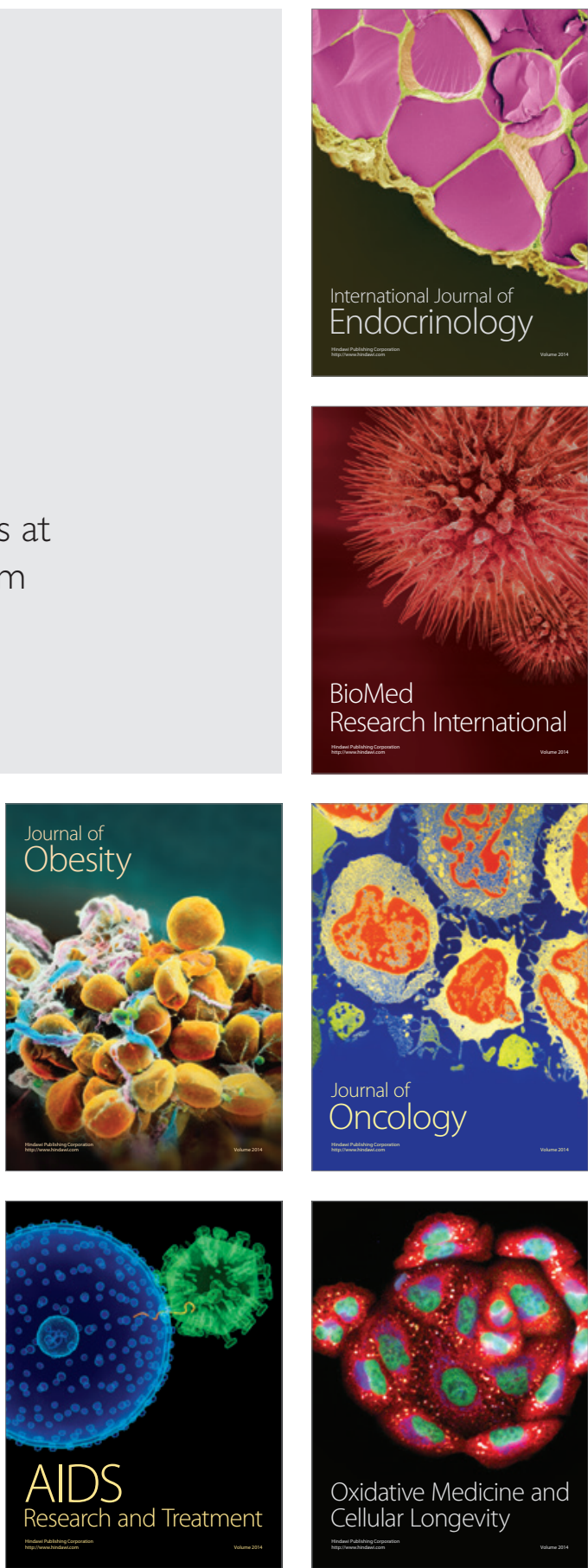